\title{
RESEARCH
}

Open Access

\section{Delay in decision and determinants for safe abortion among women at health facilities in south West Ethiopia: facility based cross sectional study}

\author{
Biru Abdissa Mizana ${ }^{1 *} \mathbb{D}$, Tsige Woyecha ${ }^{2}$ and Samuel $\mathrm{Abdu}^{3}$
}

\begin{abstract}
Background: Delayed safe abortion is the most common cause of gynecologic admission in developing countries. The study, therefore, assessed the delay decision for safe abortion and determinant factors among women at health facilities in South West Ethiopia.

Methods: Facility-based cross-sectional study was conducted among 384 women who were selected from health facilities by using simple random sampling. A pre-tested structured questionnaire was used for data collection. Data were entered into Epidata and exported to SPSS for analysis. Binary Logistic regression was used and Variables with $P$-value $<0.25$ during bivariate analysis were included in the multivariable logistic regression model. Finally, variables with $p$-value $\leq 0.05$ were judged as a statistically significant association.

Results: The magnitude of delay decision for safe abortion services was $70.8 \%(0.66,075)$. Place of residence [AOR 2.44 (95\% C.I: $(1.39,4.30)$ ], lack of formal education [AOR: 2.41 (95\% C.I:(1.08, 3.59)], level of education [AOR: 2.22 (95\% C.I: $(1.19,4.11)$ ], history of previous abortion [AOR: 3.47 (95\% C.I: $(1.74,8.6 .91)$ ] and late confirmation of pregnancy [AOR: 1.64 (95\% C.I: (1.01-2.65)] were the determinant factors for delay in decision for safe abortion.

Conclusion: This study revealed that the majority of women were delayed for the decision of safe abortion services. Place of residence of the women, lack of formal education, history of previous abortion and late confirmation of pregnancy were the determinant factors for women's decision for safe abortion. Therefore, it is better to work on awareness creation the timing of safe abortion and complication of delay abortion especially for the women from rural area.
\end{abstract}

Keywords: Delay in decision, Safe abortion, Southwest Ethiopia

\section{Background}

Abortion is expulsion from the uterus of an embryo or fetus before viability of gestational age of fewer than 20 weeks or fetal weight less than $500 \mathrm{~g}$ [1]. According to Ethiopian abortion law, abortion is the termination of pregnancy before fetal viability, which is usually taken to be less than 28 weeks from last normal menstrual period (LNMP); and if the LNMP is not known a birth weight of less than $1000 \mathrm{~g}$ [2]. Safe abortion refers to a

\footnotetext{
* Correspondence: yosan2020@gmail.com

${ }^{1}$ Department of Midwifery, Institute of Health, Jimma University, P.O.BOX:

378, Jimma, Ethiopia

Full list of author information is available at the end of the article
}

voluntary intervention to terminate an unwanted or unplanned pregnancy with skilled personnel in health facilities based on the countries abortion law [3]. Legal grounds on which abortion is permitted, according to revised abortion law of Ethiopia were when the pregnancy puts the woman's life at risk, fetal impairment or gross deformity, when pregnancy is from rape or incest (based on the woman's complaint only), when pregnancy occurs in minors (stated maternal age $<18$ years), and when the woman is physically and mentally unable to care for coming, baby [4].

Ensuring that abortion care is safe, legal and accessible for all women is important as it decreases pregnancy- 
related deaths especially in unwanted pregnancy [5]. Achieving universal access ensures that wherever a woman seeks help, when she has unprotected sex, unwanted pregnancy, she will get care that she needs, whether it be information, referral or related services. This requires good political leadership, policy development, financial resources and an adequate health-system infrastructure with a trained health-care provider [6].

Delay for safe abortion will make abortion difficult as the fetal size increase, the complication wil increase. Evidence shows that suspecting pregnancy, confirming pregnancy, deciding to have an abortion, first asking for abortion and obtaining an abortion are the specific reasons for the delay [7]. Every day, about 800 women die from pregnancy and childbirth-related causes with majority death (99\%) occurred in developing countries. Young adolescents face a higher risk of complications and death as a result of pregnancy than older women [8]. Ethiopia is among several low-income countries with the highest maternal morbidity and mortality in SubSahara Africa. According to Ethiopia demographic and health survey 2016 report, maternal mortality ratio was 412 maternal deaths per 100,000 live births [9].

The severity of complications resulting from abortion can be reduced if appropriate abortion care is sought without delay. The effect of delays in providing care has long been accepted as the main determinant of maternal death [10]. Abortion accounts for about $13 \%$ of all maternal deaths globally and accounts as high as $50 \%$ of all maternal deaths in some Sub-Saharan Africa countries [11]. Delayed abortion is the most common cause of gynecologic admission based on data collected between 1988 and 2014 from 70 studies from 28 countries, it was estimated that at least $9 \%$ of abortion-related hospital admissions have a near-miss event and approximately $1.5 \%$ end in death [12]. In Kenya, among women attending post-abortion care, $46 \%$ of women presented with late abortions [13]. In Ethiopia, abortion-related complications contribute to about $31 \%$ of maternal mortality in the country [14].

A study conducted in England showed that $79 \%$ of respondents delayed in deciding to have an abortion [7]. Similarly, a study conducted by Queen's University, Kingston researchers revealed that the prevalence of late presentation for abortion service was 70\% [15]. Finding from the Amhara region referral hospital revealed that about $29.1 \%$ of women extend the decision to seek a safe abortion service beyond 10 days [16].

According to studies from Ethiopia and India, the age of women, marital status, level of education and place residence were among factors associated with delayed decision for safe abortion services [17-19]. Similarly, finding from Canada revealed that delay for abortion was because of discouragement from friends and family
[15]. A cross-sectional study from California and China showed that delay to recognize pregnancy was a factor for the delay to decide for safe abortion services $[19,20]$. A study conducted in Kenya revealed that the decisionmaking ability of women is a factor affecting delay decision to seek safe abortion service [21]. Government and non-government organization made an effort to decrease the death associated with unsafe abortion. Among these activities making laws of the countries to allow for safe termination of pregnancies where it is not against the law [22]. The study, therefore, assessed the delay in the decision for safe abortion and determinant factors among women at health facilities in South West Ethiopia.

\section{Methods}

\section{Study design and setting}

A facility-based cross-sectional study was conducted on women who came to health facilities for safe abortion services from April 1-28, 2019. The study conducted in Jimma town abortion clinics. Jimma town is one of the towns found in Jimma zone, Southwest Ethiopia which has 18 health facilities giving safe abortion services.

\section{Population and sampling}

Study populations were all reproductive age group women who came to abortion clinics for safe abortion services during the study period. Those women with spontaneous/miscarriage or incomplete abortion and those who were seriously ill were excluded from the study. The sample size was determined by a single population proportion formula with the assumption of $50 \%$ prevalence, $5 \%$ marginal error, $95 \%$ confidence interval. Then, the final sample size was 384 . Out of 18 health facilities giving safe abortion services in the study area, 8 health facilities were selected by simple random sampling (lottery method). The health facilities patients flow were checked by reviewing the six months of medical records before the study and based on this sample size was proportionally allocated for all eight health facilities. The study participants at each health facilities were selected by simple random sampling using lottery method by using the medical record number of the available patients on each day.

\section{Data collection procedure and data quality control}

The structured questionnaire was prepared in English and translated to the regional language, Afaan Oromoo and translated back to English to check for consistency by language experts of both languages. The tools were prepared from different literature $[6,10,13,17,20]$. Reliability of the tools checked by Cronbach Alpha which was 0.839 . The pre-test was done on $5 \%$ of total sample size and some modification was done on the tools. Data 
were collected from women by face- to- face interview on exit by six Bachelor degree holder female midwives and two master holder supervisors after giving training on study purpose and tools for two days. The principal investigators and supervisors checked the collected data daily for completeness.

\section{Measurement}

Delay decision for safe abortion services was considered when the woman extends her decision of safe abortion beyond one week after she has confirmed her pregnancy in which the pregnancy was unwanted or unplanned and delay in confirming pregnancy was considered when women fail to diagnose or recognize pregnancy beyond five weeks after LNMP (last normal menstrual period). LNMP was used to confirm gestational age of her pregnancy but if she didn't know her LNMP accurately we used early ultrasound result document. Pregnancy was confirmed by reviewing urine test or ultrasound examination result of the participants.

\section{Analysis}

STROBE checklist was used to analyze and report data [13]. Data were entered into EpiData version 3.1 and exported to IBM SPSS version 23 for analysis. Both descriptive analysis like frequency and percentage and inferential statistics were done. Binary Logistic regression was employed. Odds ratio and $p$-value with a $95 \%$ confidence level were computed to judge the association between the outcome variable and independent variables. Those variables with a p-value less than 0.25 were entered into the final model. Those variables that had a p-value less than 0.05 after multivariable logistic regressions were considered as statistically significant association with outcome variables.

\section{Results}

Socio-demographic characteristics of respondents

A total of 384 women participated in the study which was $100 \%$ response rate. The mean $( \pm$ SD) age of the women was $22.3( \pm 4.4)$. Out of the total, 154 (40.1\%) of respondents who obtained safe abortion services were at the age group of 20-24 years and more than half (57.8\%) were single. More than one fourth (29.4\%) of the respondents were at primary education and 183(47.7\%) were Muslim religion followers (Table 1).

\section{Reproductive characteristics of respondents}

From the total, 119(31\%) and 43 (11.2\%) had a history of childbirth and previous abortion respectively. Twenty-six (6.8\%) respondents had a history of multiple sexual partners. From the total, 355 (92.4\%) respondents had an unwanted pregnancy and about half $(52.9 \%)$ had a history of contraceptive use (Table 2).
Table 1 Socio-demographic characteristics of participants in health facilities in South West Ethiopia, May 2019

\begin{tabular}{|c|c|c|c|}
\hline Variables & Categories & Frequency & Percentage \\
\hline \multirow[t]{3}{*}{ Age } & Less than 20 & 120 & 31.3 \\
\hline & $20-24$ & 154 & 40.1 \\
\hline & Above 24 & 110 & 28.6 \\
\hline \multirow[t]{3}{*}{ Marital status } & Single & 222 & 57.8 \\
\hline & Married & 123 & 32.0 \\
\hline & Divorced and separated & 39 & 10.2 \\
\hline \multirow[t]{2}{*}{ Residence } & Urban & 247 & 64.3 \\
\hline & Rural & 137 & 35.7 \\
\hline \multirow[t]{4}{*}{ Educational status } & No formal education & 58 & 15.1 \\
\hline & Primary education & 113 & 29.4 \\
\hline & Secondary education & 107 & 27.9 \\
\hline & Above secondary & 106 & 27.6 \\
\hline \multirow[t]{4}{*}{ Religion } & Muslim & 183 & 47.7 \\
\hline & Orthodox & 116 & 30.2 \\
\hline & Protestants & 79 & 20.6 \\
\hline & Others $^{a}$ & 6 & 1.6 \\
\hline \multirow[t]{6}{*}{ Ethnic background } & Oromo & 234 & 60.9 \\
\hline & Amara & 56 & 14.6 \\
\hline & Dawuro & 44 & 11.5 \\
\hline & Kaffa & 23 & 6.0 \\
\hline & Tigre & 9 & 2.3 \\
\hline & Others $^{\mathrm{b}}$ & 18 & 4.7 \\
\hline \multirow[t]{5}{*}{ Occupation } & Students & 174 & 45.3 \\
\hline & House wife & 84 & 21.9 \\
\hline & Unemployed & 68 & 17.7 \\
\hline & Employed & 52 & 13.5 \\
\hline & Others\# & 6 & 1.6 \\
\hline
\end{tabular}

Keys: $-{ }^{\mathrm{a}}=$ Catholic and Wakefata ${ }^{\mathrm{b}}=$ Yem, Hadiya, Gurhaghe, Wolayita \# = merchant, Daily laborers

Delay in decision and the reason of delay for safe abortion

From the total, $272[(70.8 \%)(0.66,075)]$ had a delay in the decision for getting safe abortion services. Partner objection (40.4\%), fear partner blame (69.9\%), fear of abortion may not be safe (70\%) and fear of pain from abortion procedure $(73.2 \%)$ were mentioned as the reasons for delay for safe abortion.

\section{Determinants of delay in decision for safe abortion}

After bivariate analysis, age group, residence, educational status, marital status, knowledge about free safe abortion service as safe abortion is free, history of previous abortion, being late to recognize pregnancy, and knowing presence of safe abortion had a $p$-value less than 0.25 and entered into multivariable logistic regression. After running multivariable logistic regression; residence, educational status, late 
Table 2 Reproductive characteristics of participants at health facilities in South West Ethiopia, May 2019

\begin{tabular}{llll}
\hline Variables & Categories & Frequency & Percentage \\
\hline History of child birth (Parity) & Yes & 119 & 31.0 \\
& No & 265 & 69.0 \\
History of abortion & Yes & 43 & 11.2 \\
& No & 341 & 88.8 \\
History of multiple sexual partner & Yes & 26 & 6.8 \\
& No & 358 & 93.2 \\
Pregnancy status & Wanted & 29 & 7.6 \\
& Unwanted & 355 & 92.4 \\
History of contraceptive use & Yes & 203 & 52.9 \\
& No & 181 & 47.1 \\
\hline
\end{tabular}

recognition of pregnancy and history of previous abortion were determinants of delay decision for safe abortion.

Women's residence was significantly associated with delay decision for safe abortion service. Women who came from rural were 2.44 times [AOR 2.44 (95\% CI: 1.394.30)] more likely to be delayed to decide for safe abortion services than those who came from the urban area.

Educational status was among the factors associated with delay decision for safe abortion services. Women with no education were 2.41 times [AOR 2.41 (95\% CI: 1.08-3.59)] more likely to be delayed to seek safe abortion service than women with education above the secondary school. Similarly, women with secondary educational level were 2.22 times [AOR 2.22 (95\% CI: 1.19-4.11)] more likely to be delayed for safe abortion services than women with the educational level of secondary school and above.

History of previous abortion was one of the associated factors for delay decision for seeking safe abortion services. Women who had no history of previous abortion were 3.47 times [AOR 3.47 (95\% CI: 1.74-8.6.91)] more likely to be delayed to seek safe abortion services than those who had no history of previous abortion. Those women who diagnosed their pregnancy late were 1.64 times [AOR 1.64 (95\% CI: 1.01-2.65)] more likely to be delayed for safe abortion than women who have diagnosed their pregnancy early (Table 3 ).

\section{Discussion}

This study revealed that $70.8 \%$ of the respondents delayed in the decision of getting safe abortion services. This finding was lower than finding from England and Wales in which about $79 \%$ of respondents reported a delay in deciding to have a safe abortion [23]. This

Table 3 Determinant factors of delay in decision for safe abortion services at South West Ethiopia, May 2019

\begin{tabular}{|c|c|c|c|c|c|}
\hline \multirow[b]{2}{*}{ Variables } & \multirow[b]{2}{*}{ Categories } & \multicolumn{4}{|l|}{ Decision } \\
\hline & & Delayed & Not Delayed & $\mathrm{COR}$ & $\mathrm{AOR}$ \\
\hline \multirow[t]{3}{*}{ Age group } & Less than 20 Years & $91(75.8)$ & $29(24.2)$ & 1.07 (0.59-1.95) & $0.72(0.34-1.54)$ \\
\hline & 20-24 Years & $99(64.3)$ & $55(35.7)$ & $0.62(0.36-1.06)$ & $0.64(0.34-1.22)$ \\
\hline & Above 25 Years & $82(75.5)$ & $28(24.5)$ & 1 & 1 \\
\hline \multirow[t]{2}{*}{ Residence, } & Urban & 157(63.6) & 90 (36.4) & 1 & 1 \\
\hline & Rural & $115(83.9)$ & $22(16.1)$ & $2.99(1.77-5.06)$ & $2.44(1.39-4.30)^{*}$ \\
\hline \multirow[t]{4}{*}{ Educational status, } & No formal education & $47(81)$ & $11(19)$ & $3.28(1.53-7.01)$ & $2.41(1.08-5.39)^{*}$ \\
\hline & Primary education & $83(73.5)$ & $30(26.5)$ & $2.12(1.20-3.74)$ & $1.59(0.86-2.93)$ \\
\hline & Secondary education & $82(76.6)$ & $25(23.4)$ & $2.52(1.39-4.53)$ & $2.22(1.19-4.11)^{*}$ \\
\hline & Above secondary & $60(56.6)$ & $46(43.4)$ & 1 & 1 \\
\hline \multirow[t]{3}{*}{ Marital status } & Single & $155(69.8)$ & $67(30.1)$ & $0.51(0.21-1.20)$ & $0.50(0.19-1.27)$ \\
\hline & Married & $85(69.1)$ & 38(30.9) & $0.49(0.19-1.21)$ & $0.55(0.20-1.50)$ \\
\hline & Divorced and Separated & $32(82)$ & $7(18)$ & 1 & 1 \\
\hline \multirow[t]{2}{*}{ Know presence of Legal Abortion } & Yes & $86(62.3)$ & $52(37.7)$ & 1 & 1 \\
\hline & No & 186(75.6) & $60(24.4)$ & $1.87(1.19-2.94)$ & $1.34(0.79-2.25)$ \\
\hline \multirow[t]{2}{*}{ History of abortion } & Yes & 18(41.9) & $25(58.1)$ & 1 & 1 \\
\hline & No & $254(74.5)$ & $87(25.5)$ & $4.05(2.11-7.79)$ & $3.47(1.74-6.91)^{*}$ \\
\hline \multirow[t]{2}{*}{ Timely confirming pregnancy } & Timely & $92(61.3)$ & $58(38.7)$ & 1 & 1 \\
\hline & Late & 180(76.9) & $54(23.1)$ & $2.10(1.34-3.29)$ & $1.64(1.01-2.65)^{*}$ \\
\hline \multirow[t]{2}{*}{ Knowing price affordable (free) } & Yes & 157(75.1) & $82(24.9)$ & 1 & 1 \\
\hline & No & $115(79.3)$ & $30(20.7)$ & $2.00(1.24-3.24)$ & $1.38(0.79-2.41)$ \\
\hline
\end{tabular}

${ }^{*} p$-value $<0.05$ 
discrepancy may be due to the difference in study time and also might be due to differences in socioeconomic status. Also, this finding was higher than the study conducted in Amhara Region Referral Hospitals which showed $29.1 \%$ of women delayed in the decision to seek safe abortion service [24]. This difference might be due to the difference in study setting which means a study conducted in Amhara Region Referral Hospitals conducted only in government hospitals but the current study includes both governmental and private health facilities.

Women from the rural area were 2.44 times more likely to delay safe abortion services when compared with women from urban. Similarly, a study report from Canada Queensland and Bihar and Jharkhand, India revealed that rural women were more likely delayed for safe abortion service $[17,24]$. This could be explained by the fact that those women from urban were more accessible to different social media and other sources of information concerning abortion and other related maternal health services and also women living in urban might have a good educational opportunity and due to these reasons women from urban might not be delay for safe abortion services.

The educational status of women was among the determinants of the decision of women for safe abortion services. Women with no education were 2.41 times more likely to be delayed for safe abortion service than those women with the educational status of above secondary school. Similarly, those women with secondary educational levels were 2.22 times more likely to be delayed to seek safe abortion services than those women with the educational status of above secondary school. This finding was in line with the study conducted in Bihar and Jharkhand, India which identified that lesseducated women were more likely delayed to decide for safe abortion services than those women with higher educational levels [17]. This might be because women with no formal education cannot easily access information related to reproductive health and can't easily understand the risk related to delayed abortion.

Early confirming pregnancy was also among the determinants affecting the delay of decision for safe abortion services. Those women diagnosed with their pregnancy late were 1.64 times more likely to be delayed to decide for safe abortion than those women who were diagnosed with their pregnancy early. This finding was supported by a study finding from Amhara Region Referral Hospitals which revealed those women who didn't recognize their pregnancy early were more likely to delay safe abortion services than those women who did recognize their pregnancy early [24]. These might be explained by those women who recognize their pregnancy after their fetus grown might fail into a dilemma to continue or terminating their pregnancy and they may take a long time to decide for safe abortion.

Those women who had no previous history of abortion were 3.19 times more likely to be delayed for safe abortion services when compared with those women who had a history of previous abortion. This might be because women with a previous history of abortion were experienced with the process of safe abortion and they can easily decide to have safe abortion services.

Even though this study has much strength, it has limitations like social desirability bias and we didn't consider the design effect because we gone through two stage of sampling which were selection of health facilities and selection of participants from selected health facilities. We didn't identify the reason of delay for diagnosis of pregnancy in this study. Notwithstanding this limitation, we believe that our study has very important findings in the study area and areas with similar set up to fight maternal death related to abortion.

\section{Conclusion}

The majority of women did not decide timely to get a safe abortion service which is critical for the health of women. The study also identified; place of residence, educational status, timely confirmation of pregnancy and previous history of abortion were determinants of delay decision for safe abortion. Hence, it is vital to work on awareness creation for rural women concerning the timing of safe abortion and complication of delayed abortion. We would like to recommend researcher to study about psycho-social complications of abortion and reason of delay for diagnosis of pregnancy.

\section{Abbreviations}

AOR: Adjusted odd ratio; BSc: Bachelor of Science; Cl: Confidence Interval; COR: Crude Odd Ratio; LNMP: Last Normal Menstrual Period; MSc: Master of Science; SPSS: Statistical Package for Social Science

\section{Acknowledgements \\ Our greatest thanks were for Jimma University for funding this study and Jimma town health office for their cooperation and willingness through the process of the study. Again, we would like to express our deepest gratitude for study participants for giving necessary information.}

\section{Authors' contributions \\ BAM and SA participated in designing, data analysis, interpretation of the findings and write-up of the findings. TW involved in the conception, design methods, analysis, interpretation and drafting of the manuscript. All authors read and approved the final manuscript.}

\section{Funding}

The study was funded by Jimma University. The funder has no role in the design of the study and collection, analysis, and interpretation of data and in writing the manuscript.

\section{Availability of data and materials}

The datasets used during the current study were available from the corresponding author on reasonable request. 


\section{Ethics approval and consent to participate}

Ethical clearance was obtained from Jimma University Review Board. A letter of permission was obtained from Jimma town health office for each health facility. Informed consent was taken from each participant and confidentiality was maintained by excluding the name of participants from the questionnaire and keeping the privacy during the interview time.

\section{Consent for publication}

Not Applicable.

\section{Competing interests}

The authors declare that they have no competing interests. All authors read and approved the final manuscript.

\section{Author details}

'Department of Midwifery, Institute of Health, Jimma University, P.O.BOX: 378, Jimma, Ethiopia. ${ }^{2}$ Jimma University Medical Center, Institute of Health, Jimma University, Jimma, Ethiopia. ${ }^{3}$ School of Nursing and Midwifery, Institute of Health, Jimma University, Jimma, Ethiopia.

Received: 7 October 2019 Accepted: 1 January 2020

Published online: 07 January 2020

\section{References}

1. WHO. Safe abortion:technical and policy guidance for health systems,2012

2. $\mathrm{FMOH}$. Revised technical and provcedural guidelines for safe abortion services in Ethiopia. Second ediction ed; 2014

3. Ganatra B, Gerdts C, Rossier C et al. Global, regional, and subregional classification of abortions by safety, 2010-14: estimates from a Bayesian hierarchical model. Lancet (London, England). 2017;390(10110):2372-2381 2017;

4. International Planned Parenthood Federation (IPPF). Medical abortion and women's lives: A call for action: 2015.

5. Ipas. Comprehensive Abortion Care Trainer's Manual: 2014

6. Ingham R, Lee E, Clements SJ, Stone N. Reasons for second trimester abortions in England and Wales. Reprod Health Matters. 2008:16(sup31):1829. https://doi.org/10.1016/S0968-8080(08)31375-5.

7. Tezcan S, Çavlin A. Abortions and Still birth; 2003. p. 79-88.

8. WHO. Maternal mortality fact sheet: 2015.

9. Central Statistical Agency. Ethiopia Demographic and Health Survey. Addis Ababa: Federal Democratic Republic Of Ethiopia; 2016.

10. Harries J, Orner P, Gabriel M, Mitchell E. Delays in seeking an abortion until the second trimester: a qualitative study in South Africa; 2007.

11. Ethiopian Federal Ministry of Health. In-service Training on Comprehensive Abortion Care: 2013

12. Calvert C, Owolabi OO, Yeung F, et al. The magnitude and severity of abortion-related morbidity in settings with limited access to abortion services: a systematic review and metaregression. BMJ Glob Health. 2018;3: e000692. https://doi.org/10.1136/bmjgh-2017-000692.

13. Ushie BA, Izugbara CO, Mutua MM, Kabiru CW. Timing of abortion among adolescent and young women presenting for post-abortion care in Kenya a cross-sectional analysis of nationally-representative data. BMC Women's Health. 2018;18:41.

14. Berhan Y, Berhan A. Causes of maternal mortality in Ethiopia: a significant decline in abortion related death. Ethiop J Heal Sci. 2014;8.

15. Waddington A, Hahn PM, Reid R. Determinants of late presentation for induced abortion care. J Obstet Gynaecol Canada [Internet] 2015;37(1):4045. Available from: https://doi.org/10.1016/S1701-2163(15)30361-3

16. Mulat A, Bayu H, Mellie H, Alemu A. Induced second trimester abortion and associated factors in Amhara region referral hospitals. Biomed Res Int 2015; 2015. Ahttp://dx.doi.org/https://doi.org/10.1155/2015/256534

17. Bonnen $\mathrm{Kl}$, et al. Determinants of first and second trimester induced abortion-results from a cross-sectional study taken place 7years after abortion law revisions in Ethiopia. BMC Pregnancy Childbirth. 2014;14:416.

18. Jejeebhoy SJ, Kalyanwala S, Zavier AJF, Kumar R, Jha N. Experience seeking abortion among unmarried young women in Bihar and Jharkhand, India: delays and disadvantages. Reprod Health Matters. 2010;18(35):163-74.

19. Zuo X, Yu C, Lou C, et al. Factors affecting delay in obtaining an abortion among unmarried young women in three cities in China. Asia-Pac Popul J. 2009;35-50
20. Greene BD, Kimport K. Who seeks abortions at or after 20 weeks ? Perspect Sex Reprod Health. 2013:45:210.

21. Rehnström Loi U, Lindgren M, Faxelid E, Oguttu M, Klingberg-Allvin M. Decision-making preceding induced abortion: a qualitative study of women's experiences in Kisumu, Kenya. Reprod Health. 2018 Oct 3;15(1): 166. https://doi.org/10.1186/s12978-018-0612-6.

22. Children by Choice Association. Abortion Law Reform (Women ' S Right To Choose ) Amendment Bill 2016;(June).

23. Guttmacher Institute. Unsafe Abortion in Zambia. 2009(3):1-4.

24. Sowmini CV. Delay in termination of pregnancy among unmarried adolescents and young women attending a tertiary hospital abortion services in Trivandrum, Kerala. India RHM. 2013;21(41):243-50.

\section{Publisher's Note}

Springer Nature remains neutral with regard to jurisdictional claims in published maps and institutional affiliations.
Ready to submit your research? Choose BMC and benefit from:

- fast, convenient online submission

- thorough peer review by experienced researchers in your field

- rapid publication on acceptance

- support for research data, including large and complex data types

- gold Open Access which fosters wider collaboration and increased citations

- maximum visibility for your research: over $100 \mathrm{M}$ website views per year

At BMC, research is always in progress.

Learn more biomedcentral.com/submissions 